\title{
SEMANTIC RULES, THE LAW OF ONE PRICE, PURCHASING POWER PARITY AND \\ EXCHANGE RATES: SETTING THE RECORD STRAIGHT
}

\author{
John Pippenger \\ Department of Economics \\ University of California \\ Santa Barbara, California 93106 \\ jep@ucsb.edu, 619-423-3618
}

\begin{abstract}
Semantic rules link purely theoretical terms like "price" and "electron" to things we can measure. Without them, theories cannot be tested empirically. When inappropriate, they produce false rejections. Economists routinely ignore semantic rules. Empirical journal articles essentially never mention them. More to the point, the conventional tests that reject the Law of One Price and Purchasing Power Parity never consider them. As a result, those rejections are unwarranted because such tests use inappropriate semantic rules. Both theories should be restored to not rejected and then retested using the more appropriate semantic rules described here. By using appropriate semantic rules, this paper is able to combine Covered Interest Parity and Purchasing Power Parity into a single theory that links auction markets for financial assets and commodities to auction markets for exchange rates. Using appropriate semantic rules for both theories also explains several puzzles in open economy macroeconomics and opens up broad new vistas for research.
\end{abstract}

Key words: exchange rates; arbitrage; trade; LOP; PPP; transaction costs; retail; wholesale; forward; auction; CIP; semantic rules. 


\section{Introduction}

Semantic rules link purely theoretical terms like "price" and "electron" to things we can measure. Economists routinely ignore semantic rules when testing theories. More to the point, conventional tests of the Law of One Price and Purchasing Power Parity ignore them and use inappropriate semantic rules. As a result, both theories should be restored to not rejected. Then the relevant data should be collected and the theories retested using appropriate semantic rules.

Section 2 describes the role of semantic rules in all empirical tests. Sections 3 and 4 describe the flaws in conventional tests of the Law of One Price and Purchasing Power Parity. They also provide appropriate semantic rules for both theories. Using appropriate semantic rules, Section 5 for the first time combines Purchasing Power Parity with Covered Interest Parity (CIP) to create a new approach that links auction exchange rates to auction prices for financial assets and commodities. Section 6 describes how appropriate semantic rules solve several puzzles in open-economy macroeconomics. Section 7 provides a summary with conclusions and a prediction.

To clarify the discussion, we use the acronyms PPP and LOP to refer to the pure theory behind Purchasing Power Parity and the theory on which it rests, the Law of One Price. CLOP and CPPP include the inappropriate "semantic rules" that conventional tests use to make those theories operational. ALOP and APPP describe and use the appropriate semantic rules developed below. 


\section{Semantic Rules}

We can have no more confidence in rejecting the LOP, PPP or any theory than we have in the semantic rules used to test them. ${ }^{1}$ We should have no confidence in the semantic rules used to date to test the LOP and PPP. As a result, those tests are uninformative and both theories should be restored to "not rejected" and then tested appropriately.

The following illustrates the role of semantic rules in testing theories. ${ }^{2}$ Let $\mathbf{a} \rightarrow \mathbf{b}$ represent "if $\mathbf{a}$ then $\mathbf{b}$ ". $\mathbf{a} \rightarrow \mathbf{b}$ denies that $\mathbf{a}$ is "true" and that $\mathbf{b}$ is "not true", i.e., $\mathrm{n}(\mathbf{a} \wedge \mathrm{n} \mathbf{b})$, which in turn says that either $\mathbf{a}$ is not true or $\mathbf{b}$ is true, i.e. na $\vee \mathbf{b}$. The relevant point is that $\mathbf{a} \rightarrow \mathbf{b}$ is "true" when $\mathbf{a}$ is "false" regardless of whether $\mathbf{b}$ is "true" or "not true".

Let $\mathbf{T}$ represent the LOP, PPP or any theory and $\mathbf{S}$ the corresponding semantic rules. To be empirically meaningful, some of the terms in $\mathbf{T}$ must be linked to things we can measure. A Scholastic claim that 100 angels can fit on the head of a pin is an example of a theory that is not empirically meaningful because there is no way, even in principal, to measure the number of angels.

One way to express the logical structure involved in testing theories is as follows: $\mathbf{T} \rightarrow \mathbf{S} \rightarrow(\mathbf{p} \rightarrow \mathbf{q})$ where $\mathbf{p} \rightarrow \mathbf{q}$ represents some testable implication of combining $\mathbf{T}$ and $\mathbf{S} .^{3}$ Note that rejecting $\mathbf{p} \rightarrow \mathbf{q}$ does not, by itself, reject $\mathbf{T}$. If $\mathbf{S}$ is "false", then $\mathbf{S} \rightarrow(\mathbf{p} \rightarrow \mathbf{q})$ is "true" even when the evidence rejects $(\mathbf{p} \rightarrow \mathbf{q})$. As a result, $\mathbf{T} \rightarrow[\mathbf{S} \rightarrow(\mathbf{p} \rightarrow \mathbf{q})]$ is "true" and the evidence does not reject $\mathbf{T}$. The confidence we have in rejecting $\mathrm{T}$ can be no greater than the confidence we have in accepting $\mathrm{S}$.

\footnotetext{
${ }^{1}$ The relevant literature uses different terms for "semantic rules" that mean the same thing. For example, Hempel (1966, 72-75) uses "bridge principles". See Winther (2016) for a survey of the relevant literature.

${ }^{2}$ Sarno (2005) is one of the few economists to recognize the crucial importance of the semantic rules connecting the theoretical term "price index" to something we can measure.

${ }^{3}(\mathbf{T} \wedge \mathbf{S}) \rightarrow(\mathbf{p} \rightarrow \mathbf{q})$ is an alternative way to express the logical structure, but the conclusion is the same. The falsity of $(\mathbf{p} \rightarrow \mathbf{q})$ does not, by itself, reject $\mathbf{T}$. To do that, we must accept $\mathbf{S}$ as true because a false $\mathbf{p} \rightarrow \mathbf{q}$ implies that either $\mathbf{T}$ or $\mathbf{S}$, but not necessarily both, is false.
} 
Theories constrain semantic rules. Take the law of gravity. Dropping a feather and an iron ball from the top of the leaning tower of Pisa does not reject the law because it requires a vacuum. Dropping an iron ball on the moon where it does not accelerate at 32 feet per second does not reject the law of gravity because the rate of acceleration depends on mass.

This paper points out that we should have no confidence in the semantic rules used by conventional tests to date to reject the LOP and PPP because the rules are inconsistent with the theories. As a result, the LOP and PPP should be restored to "not rejected" and then retested using appropriate semantic rules.

\section{Definitions}

Definitions of the Law of Price and Purchasing Power Parity in dictionaries, encyclopedias and Wikipedia usually include semantic rules. The following LOP and PPP are based on those definitions, but without any semantic rules.

The following is the definition for the LOP: "Effective arbitrage works to equate prices for the same good in different locations." For examples of definitions like this one, see Sarno and Taylor (2002a, 52) and Black, Hashimzade \& Myles (2012, 234). When we refer to the LOP, we mean that theory or core idea.

There are several versions of PPP. The utility version for example says that $\$ 100$ should buy the same amount of "utility" at home and abroad. But the version based on effective arbitrage and the LOP used here is by far the most common. It is the one found in most textbooks and articles as well as in extended discussions of exchange rates like Isard (1995) and Sarno and Taylor (2002a). The argument runs as follows: if the LOP holds for every good, then arbitrage works to equate the exchange rate with the "domestic price level" divided by the "foreign price level" where both "price levels" have identical weights. 
Therefore, the following is our definition for PPP: "Effective arbitrage works to equate exchange rates with ratios of price levels for the two countries where both price levels have identical weights."

Neither theory is operational. The next section considers the semantic rules used to make them operational, starting with CLOP.

\section{Rules.}

This section first reviews the inappropriate conventional semantic rules used to test the LOP and PPP. It then provides appropriate semantic rules. It begins with the conventional, but inappropriate, rejection of the Law of One Price using spot retail prices.

\subsection{Conventional LOP Rules}

Ignoring thresholds, Rogoff $(1996,649)$ describes the LOP theory for commodity markets as follows: $\mathrm{P}_{\mathrm{i}}=\mathrm{EP} \mathrm{i}_{\mathrm{i}}^{*}$ where $E$ is the domestic price of foreign exchange while $P_{i}$ and $P_{i}^{*}$ are prices for the same commodity at home and abroad.

As it stands, $\mathrm{P}_{\mathrm{i}}=\mathrm{EP}{ }_{\mathrm{i}}^{*}$ is not operational. $E, P_{i}$ and $P_{i}^{*}$ are purely theoretical terms with no links to things we can observe. Semantic rules provide those links. The relevant conventional literature including Rogoff (1996) and the articles cited in the following paragraph link $E$ to spot auction markets like those reported in the Fed's Statistical Release H10 while linking $P_{i}$ and $P_{i}^{*}$ to spot retail prices like those used in Consumer Price Indexes.

The conventional, but mistaken, view that the LOP fails rests largely on influential articles like Engel and Rogers (1996); Asplund and Friberg (2001); and Parsley and Wei (2001). They 
all link $P_{i}$ and $P_{i}^{*}$ to spot retail prices and most link $E$ to spot auction exchange rates. To the best of our knowledge, such tests never use wholesale prices.

Less widely cited research using spot auction prices and exchange rates provides much more support for the LOP. It includes Protopapadakis and Stoll (1983); Goodwin (1992); Michael, Nobay and Peel (1994); and Pippenger (2016).

As pointed out above, semantic rules must be consistent with the theory being tested. The Law of One Price is based on effective arbitrage. Therefore, the semantic rules used to test the theory must be consistent with effective arbitrage. But as pointed out below, commodity arbitrage is impossible in retail markets. In addition, commodity arbitrage involves time in transit, which makes effective arbitrage between spot markets normally impossible.

The conventional semantic rules that use spot retail prices are inappropriate because arbitrage is not possible in retail markets and normally impossible between spot markets. As a result, conventional tests of the LOP are biased toward rejection of the LOP. The same inappropriate semantic rules also create most of the foreign-exchange puzzles discussed in Section 6. Appropriate semantic rules must use prices from markets where arbitrage is routine and use prices that allow for time in transit.

\subsection{Appropriate LOP Rules}

This subsection discusses the appropriate way to test the LOP. We call it the auction and arbitrage version of the LOP, or for short ALOP.

The first serious flaw in conventional tests of the LOP like those by Engel and Rogers (1996); Asplund and Friberg (2001); and Parsley and Wei (2001) is that they ignore the 
difference between retail and auction markets. ${ }^{4}$ Whether financial or commodity, there are three major types of markets: retail, wholesale and auction. Arbitrage is impossible in retail markets, rare in wholesale markets and effective only in auction markets.

Retail commodity markets trade bread by the loaf, wholesale markets trade it by the truck load. Auction markets trade wheat by the barge load. Whether financial or commodity, transaction and information costs per dollar traded are highest in retail where the quantity traded is lowest and lowest in auction markets where the quantity traded is highest.

Low information and transaction costs combined with large volumes of "identical" products like Dark Northern Spring wheat 14\% protein promote arbitrage in auction markets. Higher information and transaction costs combined with brand names like "Kleenex" and relatively small volumes of "identical" products like particular styles of shoes limit arbitrage in wholesale markets. The relatively high costs and low volumes in retail markets help explain the absence of trade, and therefore arbitrage, in retail markets as illustrated in Figure 1.

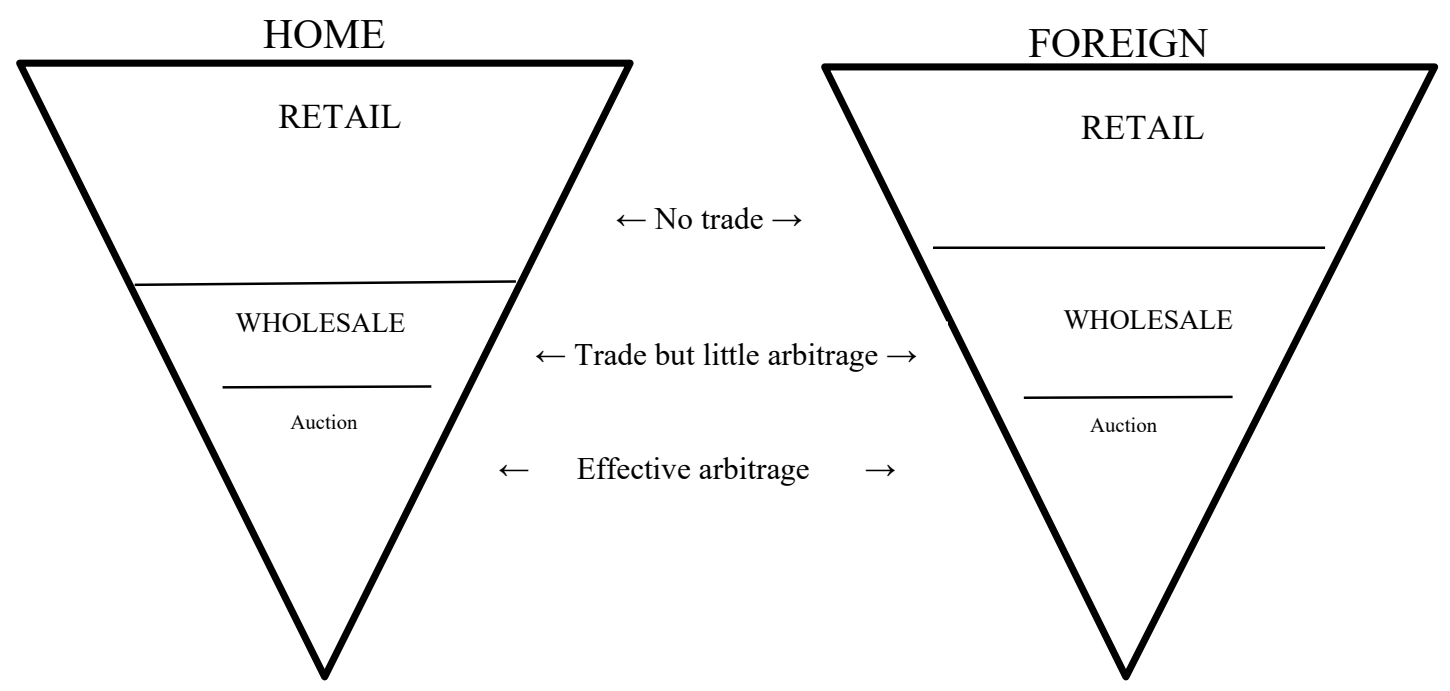

Figure 1. Arbitrage and Trade

\footnotetext{
${ }^{4}$ The role of information and transaction costs in dividing markets seems obvious, but, as far as we are aware, no one has explained how those costs divide markets into retail, wholesale and auction.
} 
Conventional tests of the LOP use commodity prices from spot retail markets, but there is no arbitrage or even trade between retail markets. As far as we are aware, tests of the LOP have never used wholesale commodity prices.

No one buys shoes from Macy's in New York and then sells them to Marshall Fields in Chicago. Someone from Chicago might buy shoes in London, Paris or New York and take them home, but that is hardly "trade".

The absence of trade between retail markets does not mean that they are not linked. A firm producing shoes in Milan sells those shoes to retailers in Chicago, London, Paris and New York. Kansas farms produce wheat that is traded in auction markets and that is milled into the flour that bakeries in Chicago, London, Paris and New York use to bake bread. Retail markets are linked, but the links are weak, indirect and work slowly as compared to arbitrage. That is why retail prices cause the Law of One Price and Purchasing Power Parity to fail completely in the short run, but provide some support in the long run. Using auction commodity prices removes this flaw.

The second serious flaw is a direct result of the first. Conventional tests of the LOP mix sticky retail commodity prices with flexible auction exchange rates. ${ }^{5}$ This mixture contributes to several of the puzzles in open-economy macroeconomics discussed in Section V because it affects conventional tests of PPP. Using auction exchange rates and auction commodity prices removes this flaw.

The third serious flaw in conventional tests of the LOP like those by Engel \& Rogers (1996); Asplund \& Friberg (2001); and Parsley \& Wei (2001) is that they use spot prices and

\footnotetext{
${ }^{5}$ The conventional LOP literature occasionally recognizes the potential problems created by mixing retail prices and auction exchange rates, but then largely ignores them.
} 
exchange rates when commodity arbitrage involves time in transit. Time in transit implies that one cannot buy a commodity spot in one location and simultaneously sell it spot in another location. Using forward auction prices for both commodities and exchange rates removes this flaw.

To the best of our knowledge, Benninga \& Protopapadakis (1988) were the first to point out the importance of time in transit for the LOP, but they concentrate on how it affects spot price differentials. ${ }^{6}$ This paper argues that time in transit changes how we should think about the LOP itself. In commodity markets, the LOP applies to forward prices and exchange rates, not spot prices and exchange rates.

Pippenger (2020) shows how arbitrage in auction markets works to equate forward commodity prices with time in transit. Let $\mathrm{W}$ represent a specific variety of wheat, $\mathrm{CC} \$$ the dollar cost of carrying W over in Gulf ports for 90 days and TC\$ the dollar cost of transporting W from Gulf ports to Rotterdam in 90 days. $^{7}$ When Gulf ports have the comparative advantage, W moves from Gulf ports to Rotterdam as long as $\log (\$ / W)_{90}<\log (\$ / €)_{90}+\log (€ / W)_{90}-$ (TC\$-CC\$). Effective arbitrage from Gulf ports to Rotterdam implies that $\log (\$ / \mathrm{W})_{90}=$ $\log (\$ / €)_{90}+\log (€ / \mathrm{W})_{90}-(\mathrm{TC} \$-\mathrm{CC} \$)$.

Let CC€ represent the cost in euros of carrying $\mathrm{W}$ over 90 days in Rotterdam and TC€ the cost in euros of transporting W from Rotterdam to Gulf ports within 90 days. If Rotterdam has the comparative advantage, W flows from Rotterdam to Gulf Ports as $\operatorname{long}$ as $\log (\$ / \mathrm{W})_{90}>\log (\$ / €)_{90}+\log (€ / \mathrm{W})_{90}+(\mathrm{TC} €-\mathrm{CC} €)$. Effective arbitrage from Rotterdam to Gulf ports implies that $\log (\$ / W)_{90}=\log (\$ / €)_{90}+\log (€ / W)_{90}$ $+(\mathrm{TC} €-\mathrm{CC} €)$.

\footnotetext{
${ }^{6}$ Coleman (2009a, 2009b) develops more general models of how time in transit affects spot price differentials.

${ }^{7}$ The analysis ignores the cost of selling W short, which just complicates the thresholds.
} 
Ignoring the thresholds, + (TC€-CC€) and - (TC\$-CC\$), effective arbitrage implies that $(\$ / €)_{90}=(\$ / W)_{90} /(€ / W)_{90}$. The Law of One price holds for forward auction prices.

Appropriate semantic rules for the Law of One Price require forward auction exchange rates and forward auction commodity prices.

\subsection{Conventional PPP Rules.}

Essentially all conventional tests of Purchasing Power Parity, implicitly or explicitly, test the arbitrage version that depends on the Law of One Price and effective arbitrage. Those tests of CPPP use spot auction exchange rates and spot retail or wholesale commodity prices. While there is an ongoing debate over whether or not Purchasing Power Parity is useful in the long run, we know of no tests that support short-run Purchasing Power Parity. For that debate see Kouretas (1997); Kargbo (2009); O’Connell (1998); Papell (2002); and Pesaran et al (2009).

Rogoff $(1996,650)$ describes PPP as follows: $E=\sum \mathrm{P}_{\mathrm{i}} / \sum \mathrm{P}_{\mathrm{i}}^{*} \cdot{ }^{8}$ That theoretical statement of Purchasing Power Parity requires semantic rules to be operational. The implicit semantic rule for $E$ is that it is a spot auction price. The explicit semantic rule for "price" is that it is a spot consumer, i.e., retail, price. The sums $\sum P_{i}$ and $\sum P_{i}^{*}$ are explicitly over spot consumer price indexes. Note that while Rogoff recognizes that Purchasing Power Parity is based on the Law of

\footnotetext{
${ }^{8}$ Officer (1976) does something similar.
} 
One Price, he does not point out that the law implies that $\sum \mathrm{P}_{\mathrm{i}}$ and $\sum \mathrm{P}_{\mathrm{i}}^{*}$ should have identical weights.

Rogoff categorically rejects conventional PPP saying that tests repeatedly reject the theory for stable monetary regimes. He cites Krugman (1978) and Frenkel (1981) as examples. More recent tests of Purchasing Power Parity using similar inappropriate semantic rules also reject the theory. See for example Xi et all (2021) and Nagayasu (2021).

As pointed out above, semantic rules must be consistent with the theory being tested. Purchasing Power Parity is based on the Law of One Price and effective arbitrage. Therefore, the semantic rules used to test the theory must be consistent with the Law of One Price and effective arbitrage. But conventional semantic rules for PPP are inconsistent with the theory because commodity arbitrage is impossible in retail markets and rare in wholesale markets. In addition, commodity arbitrage involves time in transit, which prevents direct arbitrage between spot commodity markets.

These inappropriate conventional semantic rules seriously bias tests of PPP toward rejection. The next subsection describes the appropriate semantic rules for testing Purchasing Power Parity.

\subsection{Appropriate PPP Rules.}

This subsection first reviews the flaws in conventional semantic rules and then describes the appropriate rules. Statistical tests of Purchasing Power Parity that use inappropriate spot retail prices start as far back as Yeager (1958) and continue into 2021. See Xie et all (2020) and Nagayasu (2021).

The first flaw in conventional tests of PPP is that they use retail or wholesale commodity prices. But there is no trade and, therefore, no arbitrage in retail markets and only limited 
arbitrage in wholesale markets. Whatever conventional tests of PPP test, it is not the PPP based on the LOP because the LOP is based on arbitrage and arbitrage is impossible between retail markets and limited between wholesale markets. Using auction commodity prices where arbitrage is routine removes this flaw.

The second flaw is that conventional PPP tests mix retail commodity prices with auction exchange rates. This mixture causes most of the open-economy puzzles discussed in Section V, especially the belief in "excessive" volatility. Using auction exchange rates and auction commodity prices removes this flaw.

The third flaw is that conventional tests use spot prices. But time in transit rules out direct arbitrage between spot markets. Whatever conventional tests of PPP test, it is not the PPP based on the LOP and effective arbitrage. Appropriate semantic rules for Purchasing Power Parity should use forward auction exchange rates and forward auction commodity prices.

It is convenient at this point to ignore the thresholds described above and write the appropriate test equation for Purchasing Power Parity as follows:

$$
F(t+y)=\Pi(t+y) / \Pi *(t+y)
$$

where $\Pi(t+y)$ is a domestic basket of forward auction prices at $t$ for $t+y$ and the interval between $t$ and $y$ is large enough to cover time in transit, $\Pi^{*}(t+y)$ is a foreign basket of forward auction prices at $t$ for $t+y$ with the same weights as $\Pi(t+y)$ and $F(t+y)$ is a forward auction exchange rate at $t$ for $t+y$. With effective arbitrage, eq. (1) should hold even in the short run.

There are far fewer auction commodity markets than retail commodity markets, but there are probably more auction commodity markets than most economists realize. In addition, unlike retail prices that are "sticky", auction commodity prices like auction exchange rates are, to a reasonable first approximation, usually martingales. Table 1 in Pippenger (2020) lists several 
different auction commodity prices, some with more than one location, and provides a simple test for a martingale.

Using eq. (1), the next section develops an asset and commodity theory of exchange rates, i.e., ACTFX. For ACTFX it is convenient to express eq. (1) logarithmically as $f(t+y)=\pi(t+y)-\pi^{*}(t+y)$

\section{ACTFX}

This section develops a theory of exchange rate determination based on arbitrage in auction markets for both financial assets and commodities. It begins with Covered Interest Parity where $i(t+y)$ is the domestic interest rate at $t$ with maturity $y$ and $i *(t+y)$ is the foreign interest rate at $t$ with maturity $y$. Then it combines Covered Interest Parity and Purchasing Power Parity by replacing the $\log$ of the forward rate in CIP with $\pi(t+y)-\pi^{*}(t+y)$ from APPP.

\subsection{Covered Interest Parity}

There is strong empirical support for CIP. See for example Akram, Farooq and Sarno (2008). Ignoring transaction costs, CIP says that $F(t+y) / S(t)=[1+i(t+y)] /[1+i *(t+y)]$, where $S(t)$ is the spot exchange rate and $F(t+y)$ is the forward rate at $t$ for $t+y$ as in eq. (1) above. CIP is usually expressed in a logarithmic approximation as $f(t+y)-s(t)=i(t+y)-i^{*}(t+y)$ where $s(t)$ is the $\log$ of $S(t)$.

CIP is an example of the ALOP in financial markets with all prices auction prices where there is no time in transit. Suppose $f(t+y)$ equals $s(t)$, but $i^{*}(t+y)$ is less than $i(t+y)$. Ignoring transaction costs, there are risk-free profits. Large money market banks borrow a million euro at $i^{*}(t+y)$, use that million euro to buy a million dollars, invest that million dollars at the higher $i(t+y)$ and sell those dollars forward for euros, earning an almost instantaneous risk-free profit of 
$€ 1,000,000.00[1+i(t+y)]$ minus $€ 1,000,000.00[1+i *(t+y)]$. As Akram, Farooq and Sarno (2008) point out, in financial auction markets opportunities for such profits do not last much longer than a few minutes.

After accounting for the different transaction costs and the fact that commodities require time in transit, we should expect arbitrage to be as effective in auction commodity markets as in auction financial markets. Why would traders in commodity auction markets ignore risk-free profits when traders in financial auction markets do not?

The usual interpretation of CIP is that $i(t+y)-i^{*}(t+y)+s(t)$ determines $f(t+y)$. That interpretation is reasonable because the volume of transactions in spot foreign exchange markets is greater than in any individual forward market. But that interpretation is less convincing when we compare the combined volume of transactions in all forward markets to the volume in the spot market.

Eq. (2) is an aggregate version of CIP where each maturity is weighted by the relative volume of transactions in forward markets, $w_{y}$. As far as we are aware, no one has ever expressed CIP in this way before. If CIP holds for every maturity, then eq. (2) holds.

$$
s(t)=\sum_{y=1}^{N} w_{y}\left\{f(t+y)-\left[i(t+y)-i^{*}(t+y)\right]\right\}
$$

\subsection{ACTFX.}

The next step to ACTFX combines Purchasing Power Parity and CIP. Replace $f(t+y)$ in eq. (2) with $\pi(t+y)-\pi^{*}(t+y)$ where $y$ is large enough to cover time in transit, e.g., $n$. That replacement produces eq. (3), an ACTFX that ignores thresholds.

$$
s(t)=\sum_{y=n}^{N} w_{y}\left\{\pi(t+y)-\pi^{*}(t+y)-\left[i(t+y)-i^{*}(t+y)\right]\right\}
$$


ACTFX describes how the interaction between auction markets for financial assets, $i(t+y)-$ $i^{*}(t+y)$, and auction markets for commodities, $\pi(t+y)-\pi^{*}(t+y)$, affects spot exchange rates through arbitrage. For commodity markets alone to determine spot exchange rates, $\sum_{y=1}^{N} w_{y}\left[i(t+y)-i^{*}(t+y)\right]$ must be zero. For financial markets alone to determine spot exchange rates, $\sum_{y=1}^{N} w_{y}\left[\pi(t+y)-\pi^{*}(t+y)\right]$ must be zero. That last condition can help explain why the asset approach to exchange rates fails.

Two advantages of eq. (3) are that it should hold for levels as well as changes because it does not use price indexes and that data should be available on a daily basis. There also is no reason to dismiss short-run ACTFX out of hand.

Eq. (3) is directly relevant only for those countries with appropriate auction markets. That requirement restricts it to developed countries and not to all developed countries. But the economics behind eq. (3) applies to all countries. At the retail level all goods are non-traded. Arbitrage is impossible in retail markets, rare in wholesale markets and routine only in auction markets. In addition, trading commodities involves time in transit. But arbitrage should be effective in both auction commodity and auction financial markets. With effective arbitrage in auction markets, eq. (3) should hold in both the long run and short run.

\section{Puzzles.}

In Rogoff (1996), The Purchasing Power Parity Puzzle, the puzzle is the high short-run volatility of real exchange rates combined with the slow rate at which those half-lives die out. His explanation is that, in spite of progress, international commodity markets remain highly 
segmented. When Rogoff refers to international commodity markets being highly segmented, he means retail commodity markets. ${ }^{9}$

The distinction between retail, wholesale and auction markets for commodities provides a better explanation. By their very nature, international retail markets are highly segmented and always will be because of their high transaction costs. But international auction markets are highly integrated and have been for a long time.

In the years since 1996, the puzzles have increased and been refined. Rogoff's puzzle has become three related puzzles: "excessive" exchange rate volatility, short-run versus long run and long half-lives for real Purchasing-Power-Parity deviations. Two additional puzzles are that Purchasing Power Parity appears to work during inflation, but not in normal times, and the lack of any fundamentals that explain the behavior of exchange rates.

The following subsections take up these puzzles in the following order: (a) Purchasing Power Parity works when there is inflation, but not in normal times, (b) It may work in the long run, but not in the short run, (c) Long half-lives for real Purchasing Power Parity differentials, (d) Exchange rate volatility appears excessive, and (e) An apparent lack of fundamentals.

\subsection{Inflation versus Normal.}

Frenkel (1981) is a seminal source of the idea that Purchasing Power Parity works during inflation but fails in normal times. Using wholesale and cost of living price indexes, he compares the performance of Purchasing Power Parity during the inflationary 1920s to its performance during the "normal" 1970s. His results for wholesale and cost of living indexes are

\footnotetext{
9 At one point, p. 650, Rogoff indirectly refers to auction markets. The prices for gold in his Table 2 appear to be from auction markets. But he quickly dismisses such prices for PPP.
} 
similar. He concludes that Purchasing Power Parity worked during the inflationary 1920s, but failed during the more normal 1970s.

Davutyan and Pippenger (1985) point out that his conclusion is a statistical illusion due to thresholds. A simple example makes their point. Suppose CPPP is essentially constant and exchange rates never exceed the thresholds. CPPP always holds, but $\bar{R}^{2} s$ are close to zero and regression coefficients imprecise because within the wide thresholds there is no link between relative price indexes and exchange rates.

Now consider the case where CPPP and exchange rates both rise due to inflation and exchange rates often exceed the thresholds. CPPP often fails, but $\bar{R}^{2} s$ are much larger and coefficients more precise. In the presence of thresholds, we must interpret regression results carefully.

This puzzle is primarily the result of mixing retail prices with auction exchange rates in the context of thresholds. In normal times CPPP volatility is small due to sticky retail prices while thresholds are very wide because at retail all goods are non-traded. Wholesale prices are less sticky and thresholds narrower, but empirically they do only slightly better in normal times.

As inflation increases, retail and wholesale prices become more flexible. Thresholds are less important. In hyperinflations like those in the 1920 s even retail prices become very flexible and threshold effects largely disappear.

With auction prices, the difference between inflationary and normal times should largely disappear. With or without inflation, auction prices are very flexible and thresholds relatively narrow. The problem with $\bar{R}^{2}$ largely disappears and with it most of the distinction between inflationary and normal times. 


\subsection{Long Run versus Short Run.}

The evidence clearly rejects CPPP for the short-run. But there is some support for it as a long-run theory. In addition to Sarno and Taylor (2002b) and Taylor (2006), see the articles cited above regarding the long-run debate.

The solution for this puzzle is essentially the same as for Inflation versus Normal. Replace "Inflation" with "long run" and "Normal" with "short run". In the short run, relative CPPP fails because sticky retail prices, time in transit, wide thresholds and the lack of arbitrage disconnect spot exchange rates from spot retail prices. In the long run, retail and wholesale prices become more flexible, thresholds narrower and weak economic links strengthen, producing more longrun support for PPP, particularly for wholesale prices.

With forward auction prices, the difference between short run and long run should largely disappear. In all runs, auction prices are flexible and thresholds narrow because information and transaction costs per dollar traded are relatively low. ${ }^{10}$

\subsection{Long Half-Lives.}

Obstfeld and Rogoff (2000) list long half-lives for real CPPP differentials as one of the six major puzzles in international macroeconomics. Again, the primary sources of the problem are sticky retail prices, wide thresholds and weak economic links between retail markets combined with volatile exchange rates. Half-lives using CPPP are long because most tests use prices from retail markets where all goods are non-traded. It should not be a surprise that real price differentials between non-traded goods have half-lives measured in years.

\footnotetext{
${ }^{10}$ Without restrictions, appealing to information and transaction costs can explain anything, which means they explain nothing. Our position is simple. We assume that such costs behave like other costs. More precisely, they behave like the postulates on costs in Alchian (1959).
} 
Half-lives using APPP should be much shorter. Auction prices are far more flexible and thresholds are much narrower because information and transaction costs per dollar are much smaller in auction markets where commodities are traded by the shipload rather than by the pound or ounce.

APPP price levels do not yet exist. But comparing CLOP to ALOP provides some insight into what we can expect. As pointed out above, the evidence rejects CLOP. But the evidence supports ALOP. As Pippenger (2016) reports, real half-life differentials for commodity auction prices are measured in just a few weeks.

\subsection{Excessive Volatility.}

As is well known, the volatility of exchange rates is much larger than the volatility of corresponding CPPP. As an example of "excessive" volatility with CPPP, using monthly data from FRED for 1975 to 2020, Pippenger (2020) shows that the variance of the change in the log of the Canadian price of U.S. dollars is 0.000226 while the variance in the change in the log of the corresponding CPPP using consumer price indexes is only 0.000018 , a ratio of over 12 to 1 . This difference in volatility is the primary evidence behind the belief that exchange-rate volatility is "excessive".

The explanation for this puzzle is similar to the one for the three previous puzzles. Exchange rates are from auction markets while commodity prices are from retail markets. We are unaware of any articles comparing the volatility of relative wholesale price indexes to the volatility of exchange rates.

No one should be surprised to find that the volatility of the auction price of a common variety of wheat on the Chicago Board of Trade, whose price changes from minute to minute, is 12 times greater than the volatility of the retail price of bread in Chicago grocery stores, whose 
price often does not change for days or weeks. Why are we surprised by a ratio of 12 to 1 when we compare auction exchange rates to relative retail price levels?

We do not yet have APPP data, but we do have individual auction prices, which can give us some insight into APPP. At least it compares auction to auction. Using weekly data from spot auction markets, Bui and Pippenger (1990) find that the volatility of exchange rates implied by relative prices, e.g. $P_{i} / P_{i}^{*}$ using auction prices, is slightly greater than the volatility of actual spot exchange rates. Instead of 12 to 1 , using auction commodity prices, the ratio is about 1 .

Of course, their results apply to spot auction markets, not forward auction markets. In addition, they use individual auction prices, not price levels. But their results suggest that using APPP rather than CPPP will greatly reduce, if not eliminate, the primary evidence for excessive volatility.

\subsection{Exchange-Rate Disconnect.}

The exchange-rate disconnect refers to the lack of any clear link between exchange rates and economic fundamentals. It is another one of the six major puzzles in Obstfeld and Rogoff (2000). APPP and ACTFX have the potential to solve this puzzle.

Theory suggests that relative price levels and financial markets are two important fundamentals. CPPP fails for the reasons discussed above. Why the asset approach to exchange rates fails is not yet obvious, possibly because it ignores relative price levels.

If future research using appropriate semantic rules supports Purchasing Power Parity, that result will provide a strong link between economic fundamentals and exchange rates. ACTFX could provide an even stronger link. Using auction markets for commodities and assets, ACTFX combines relative commodity price levels and financial markets. It resolves the exchange-rate 
disconnect by linking exchange rates to commodity and asset markets. Only careful research can determine whether or not that potential is realized.

Collecting the data necessary to compare the CLOP and CPPP to the ALOP and APPP will take time and be expensive. Is the game worth the candle? The ability of APPP and/or ACTFX to explain so many puzzles suggests that the game is worth the candle.

\section{Summary, Conclusions and a Prediction.}

Semantic rules connect purely theoretical terms like "price" to things we can observe like prices in retail, wholesale and auction markets. Economists routinely ignore semantic rules. Section 2 lays out the logic behind the crucial role played by semantic rules in testing all theories. It points out that, to have any confidence in the rejection of a theory, the semantic rules used in that rejection must be consistent with the theory.

Using the Law of One Price and Purchasing Power Parity as examples, this paper shows how ignoring semantic rules leads to false rejections. Section 3 describes the essential theory behind the Law of One Price and Purchasing Power Parity devoid of any semantic rules. For the Law of One Price it is: "Effective arbitrage works to equate prices for the same good in different locations." For Purchasing Power Parity it is: "Effective arbitrage works to equate exchange rates with ratios of price levels for the two countries where both price levels have the same weights."

Subsections 4.1 and 4.3 describe the semantic rules used in conventional tests, and rejections, of the Law of One Price and Purchasing power parity. The relevant characteristics are: (1) commodity prices are retail, or occasionally wholesale for Purchasing Power Parity, (2) exchange rates are auction prices and (3) exchange rates and commodity prices are both spot. 
These characteristics are inconsistent with the Law of one Price and Purchasing Power Parity as defined above.

Subsections 4.2 and 4.4 describe the appropriate semantic rules. Semantic rules for both theories should use auction exchange rates and auction commodity prices, because arbitrage is routine in auction markets, but not in retail or wholesale markets. In addition, semantic rules should use forward auction exchange rates and commodity prices to account for time in transit.

Section 5 shows how it is possible to combine Covered Interest Parity and Purchasing Power Parity when Purchasing Power Parity uses appropriate semantic rules. This combination provides an explanation for the determination of exchange rates based on effective arbitrage in auction markets for both financial assets and commodities.

Section 6 shows how using the appropriate semantic rules for the Law of One Price and/or Purchasing power Parity explains several of the important puzzles associated with exchange rates like "excessive volatility".

The paper ends with four conclusions and a prediction. Conclusions: (1) The conventional rejection of the Law of One Price and Purchasing Power Parity should be put aside and the theories restored to the status of not rejected. (2) The data needed to test the Law of One Price and Purchasing Power Parity appropriately, i.e., forward auction exchange rates and commodity prices, should be collected and used to test the theories. (3) The theory of exchange rate determination based on combining Covered Interest Rate Parity and Purchasing Power Parity described in Section 5 should be tested against alternatives like the asset approach to exchange rates. (4) No matter what theory they are testing, economists need to pay much closer attention to semantic rules so that they avoid mistaken rejections. 
Prediction: If, as the evidence supporting the Law of One Price using spot auction prices suggests, forward auction prices produce strong empirical support for the Law of One Price and Purchasing Power Parity, it will fundamentally change how we think about exchange rates, cast even more doubt on the asset approach to exchange rates and raise serious questions about open economy IS-LM. It will also open many new vistas for research.

FUNDING: This research received no external funding.

DATA: No data used.

ACKNOWLEDGEMENTS: I want to thank Mike Pippenger, Patricio A. Fernandez and Michael Bordo for their comments. Any remaining errors are of course mine.

CONFLICTS OF INTERESTS: The author declares no conflict of interest. 


\section{REFERENCES}

Akram, Q. Farooq, Dagfinn Rime, and Lucio Sarno, “Arbitrage in the Foreign Exchange Market: Turning on the Microscope.” Journal of International Economics, 76 (2008), 237-253.

Alchian, Armen, "Costs and Outputs," in The Allocation of Economic Resources M. Abramovitz et al, eds. (Stanford, CA: Stanford University Press, 1959).

Asplund, Marcus, and Richard Friberg, "The Law of One Price in Scandinavian Duty-Free Stores” American Economic Review, 91 (2001), 1072-1083.

Benninga, Simon, and Aris Protopapadakis, "The Equilibrium Pricing of Exchange Rates and Assets when Trade Takes Time,’ Journal of International Money and Finance, 7 (1988), 129-149.

Black, John, Nigar Hashimzade, and Gareth Myles, A Dictionary of Economics, $4^{\text {th }}$ edition. (Oxford: Oxford University Press).

Bui, Nhuong, and John Pippenger, "Commodity prices, exchange rates and their relative volatility,” Journal of International Money and Finance, 9 (1990), 3-20.

Coleman, Andrew, “A Model of Spatial Arbitrage with Transport Capacity Constraints and Endogenous Transport Prices,” American Journal of Agricultural Economics, 91 (2009a), $42-56$.

Coleman, Andrew, "Storage, Slow Transport, and the Law of One Price: Theory with Evidence from Nineteenth-Century U.S. Corn Markets,” The Review of Economics and Statistics, 91 (2009b), 332-350.

Crucini, Mario, and Christopher Telmer, "Microeconomic sources of real exchange rate variation,” Review of Economic Dynamics 38 (2020), 22-40. 
Dang, Vinh Q. T., Erin So, Alan Yang, and Chan Kenneth, "China and international market integration: Evidence from the law of one price in the Middle East and Africa." North American Journal of Economics and Finance, 54 (2020), 1-14.

Davutyan, Nurhan, and John Pippenger, "Purchasing Power Parity Did Not Collapse During the 1970s," The American Economic Review, 75 (1985), 1151-1158.

Engel, Charles, and John H. Rogers, "How Wide Is the Border?” American Economic Review 86 (1996), 1112-1125.

Frenkel, Jacob A., “The Collapse of Purchasing Power Parities during the 1970s.” European Economic Review, 16 (1981), 145-65.

Goodwin, Barry K., "Cointegration Tests of the Law of One Price in International Wheat Markets," Review of Agricultural Economics, 14 (1992), 117-124.

Hempel, Carl G., Philosophy of Natural Science, (Englewood Cliffs, N.J.: Prentice-Hall, Inc. 1966).

Isard, Peter, Exchange Rate Economics, (Cambridge, England: Cambridge University Press, 1995).

Kargbo, Joseph M., "Financial globalization and purchasing power parity in the G7 countries." Applied Economics Letters, 16 (2009), 69-74.

Kim, Yoonbai, "Purchasing Power Parity: Another Look at the Long-run Data.” Economic Letters, 32 (1990), 339-344.

Kouretas, Georgios P., "The Canadian Dollar and Purchasing Power Parity during the Recent Float," Review of International Economics, 5 (1997), 467-477.

Krugman, Paul R., "Purchasing Power Parity and Exchange Rates: Another Look at the Evidence,” Journal of International Economics, 8 (1978), 397-407 
Michael, Panos, A. Robert Nobay, and David A. Peel, "Purchasing power parity yet again:

evidence from spatially separated commodity markets.” Journal of International Money and Finance, 13 (1994), 637-657.

Murray, J.M., and D.H. Papell, “The purchasing power parity persistence paradigm”, Journal of International Economics, 56 (2002), 1-19.

Nagayasu, Jun., “Casual and frequency analyses of purchasing power parity.” Journal of International Financial Markets, Institutions \& Money, 71 (2021), 1-22.

Obstfield, Maurice, and Kenneth Rogoff, “The Six Major Puzzles in International Macroeconomics: Is There a Common Cause?” NBER Macroeconomics Annual, 15 (2000), 339-390.

O’Connell, Paul, "The overvaluation of purchasing power parity.” Journal of International Economics, 44 (1998), 1-19.

Officer, Lawrence H., “The Purchasing-Power-Parity Theory of Exchange Rates: A Review Article,” IMF Staff Papers, 23 (1976), 1-60.

Papell, David H., "The great appreciation, the great appreciation, and the purchasing power parity hypothesis,” Journal of International Economics, 57 (2002), 51-82.

Parsley, David C., and ShangJin Wei, "Explaining the border effect: the role of exchange rate variability, shipping costs and geography,” Journal of International Economics, 55 (2001), 87-105.

Pesaran, M. Hashem, Ron P. Smith, Takashi Yamagata, and Lyudmyla Hvozdyk, "Pairwise Tests of Purchasing Power Parity,” Econometric Reviews, 28 (2009), 495-521.

Pippenger, John, "Commodity Arbitrage and the Law of One Price: Setting the Record Straight." Theoretical Economic Letters, 6 (2016), 1017-1033. 
Pippenger, John, “The Law of One Price, Purchasing Power Parity and Exchange Rates: Setting the Record Straight," UC Santa Barbara: Department of Economics working Paper 2020. Protopapadakis, Aris, and Hans R. Stoll, "Spot and Futures Prices and the Law of One Price." The Journal of Finance, 38 (1983), 1431-1455.

Rogoff, Kenneth, “The Purchasing Power Parity Puzzle.” Journal of Economic Literature, 34 (1996), 647-668.

Sarno, Lucio, "Viewpoint: Towards a solution to the puzzles in exchange rate economics: where do we stand?" Canadian Journal of Economics, 38 (2005), 673-708.

Sarno, Lucio, and Mark P. Taylor, The Economics of Exchange Rates, (Cambridge U.K.: Cambridge University Press 2002a).

Sarno, Lucio, and Mark P Taylor, "Purchasing Power Parity and the Real Exchange Rate." IMF Staff Papers, 49 (2002b), 65-105.

Smallwood, A. D., "Measuring the persistence of deviations from purchasing power parity with a fractionally integrated STAR model,” Journal of International Money and Finance, 27 (2008), 1161-1176.

Taylor, Mark P., "Real exchange rates and Purchasing Power Parity: mean-reversion in economic thought," Applied Financial Economics, 16 (2006), 1-17.

Winther, R.G., "The Structure of Scientific Theories." in The Stanford Encyclopedia of Philosophy, Edward N. Zalta, ed. (Stanford, CA.: Stanford University, 2016 Winter edition).

Xie, Zixiong, Shyh-Wei Chen, and Chun_Kuei Hsieh, "Facing up to the polysemy of purchasing power parity: New international evidence.” Economic Modeling, 98 (2021), 247-265. 
Yeager, Leland, “A Rehabilitation of Purchasing Power Parity.” Journal of Political Economy, 66 (1958), 516-530. 